\title{
FORMAÇÃO DE PEDAGOGOS: TRAJETÓRIAS E PERSPECTIVAS DOCENTES
}

\author{
FORMACIÓN DE PEDAGOGOS: TRAYECTORIAS Y PERSPECTIVAS
}

\author{
TEACHER TRAINING: TRAJECTORIES AND PERSPECTIVES
}

\author{
Andréia MORÉS ${ }^{1}$ \\ Neiva Senaide Petry PANOZZO²
}

RESUMO : O presente texto contempla um recorte da pesquisa sobre os processos de formação docente construídos durante os 50 anos do curso de Pedagogia da Universidade de Caxias do Sul (UCS). As informações foram obtidas em relatos de professores aposentados e em atividade, com o objetivo de identificar os contextos da docência desses profissionais da Educação e suas contribuições para a constituição da identidade do Curso de Pedagogia. Os subsídios metodológicos da investigação apoiam-se na abordagem qualitativa de relatos autobiográficos e entrevistas, tendo seu aporte teórico embasado em Fentress e Wickham (1992) que discorrem sobre vinculações e relações entre duas dimensões da memória individual e coletiva. Os resultados revelam que, por longos anos, a formação de professores ocorreu em ambiente movido pelo ideário tecnicista, o que perdurou por várias décadas, e também sinalizam que, na atualidade, há um movimento de concepções e teorias que apontam mudanças nos paradigmas educacionais, para uma concepção crítica e dialógica.

PALAVRAS-CHAVE: Docência. Formação de pedagogos. Curso de Pedagogia

RESUMEN: En el presente texto se hace un recorte de la investigación acerca de los procesos de formación docente que han sido construidos a lo largo de los 50 años del curso de Pedagogía de la Universidad de Caxias do Sul (UCS). Las informaciones proceden de informes de profesores jubilados y activos con el objetivo de identificar los contextos de la docencia de estos profesionales de Educación y sus contribuciones para la constitución de la identidad del Curso de Pedagogía. Los subsidios metodológicos de la investigación se apoyan en el abordaje cualitativo de informes autobiográficos y entrevistas, con aporte teórico basado en Fentress y Wickham que discurren sobre vinculaciones y relaciones entre las dos dimensiones de la memoria, la individual y la colectiva. Los resultados reflejan que, a lo largo de años, la formación de profesores ocurrió en un ambiente movido por la ideología tecnicista, que ha perdurado durante varias décadas. Además, señalan que en la actualidad hay un movimiento de concepciones y teorías que apuntan a cambios en los paradigmas educacionales hacia un diseño crítico y dialógico.

PALABRAS-CLAVE: Docencia. Formación de pedagogos. Curso de Pedagogía.

\footnotetext{
${ }^{1}$ Universidade de Caxias do Sul (UCS), Caxias do Sul - RS - Brasil. Professora do Programa de Pós-Graduação em Educação (PPGEdu). ORCID <https://orcid.org/0000-0002-6982-0803>. E-mail: anmores18@ hotmail.com

${ }^{2}$ Universidade de Caxias do Sul (UCS), Caxias do Sul - RS - Brasil. Doutora em Educação. Professora aposenta pela Universidade de Caxias do Sul. ORCID <https://orcid.org/0000-0001-6921-9084>. E-mail: nsppanoz@ucs.br
}

RIAEE - Revista Ibero-Americana de Estudos em Educação, Araraquara, v. 14, n. 1, p. 253-264, jan./mar., 2019. E-ISSN: $1982-5587$. 
ABSTRACT: The current text contemplates a cut-off of the research about teacher training processes constructed over the 50 years of the Pedagogy course at the University of Caxias do Sul (UCS). The information has been obtained from reports of retired and active teachers with the objective of identifying the teaching contexts of these Education professionals and their contributions for the constitution of the Pedagogy Course identity. The investigation methodological subsidies have support on the qualitative approach of the autobiographic reports and interviews with theoretical input based on Fentress and Wickham who discuss about ties and relations between the two memory dimensions, the individual and the collective ones. Findings show that over many years the education of teachers occurred in an environment fostered by the technical ideology that lasted for several decades. They also evidence that nowadays there is a movement of concepts and theories that point out to changes of educational paradigms into a critical and dialogical design.

KEYWORDS: Teaching. Education of teachers. Pedagogy course.

\section{Introdução}

O presente estudo está ancorado na pesquisa "Percurso, memórias e identidades na formação de pedagogos", realizada junto ao Curso de Pedagogia da Universidade de Caxias do Sul (UCS), vinculada ao Programa de Pós-Graduação e ao Observatório em Educação. O objetivo norteador deste estudo contemplou os processos de formação docente construídos durante os 50 anos do Curso de Pedagogia da Instituição.

Adentrar nos estudos da educação superior, mais especificamente no curso de Pedagogia, remete à reflexão sobre a formação docente na universidade. No cenário desta investigação tem-se o Curso de Pedagogia da Universidade de Caxias do Sul/RS, com a necessidade de mapear, documentar e registrar trajetórias de professores desse curso quanto às suas experiências no processo de constituição de significados, na condição de formadores de novos docentes.

No desenvolvimento desta pesquisa utiliza-se a abordagem qualitativa, em desdobramentos com a pesquisa documental e autobiográfica, com a respectiva análise discursiva dos dados. Os sujeitos da pesquisa foram professores do curso de Pedagogia aposentados e em exercício profissional, e seus depoimentos viabilizaram a sistematização dos saberes construídos em diferentes contextos de formação.

Nessa trajetória, a UCS, mais especificamente o Curso de Pedagogia, respalda a importância da presente pesquisa, de forma a potencializar os processos de formação docente vividos, historicamente, visando à qualidade nos processos de formação pedagógica na atualidade. 


\section{Pedagogia e as interfaces teóricas}

Pensar sobre a pedagogia e suas interfaces teóricas faz com que, inicialmente, se lance um olhar para o processo histórico. Neste artigo, faz-se um recorte, partindo da pedagogia tradicional, passando pela pedagogia nova, pela pedagogia tecnicista, adentrando nas contribuições da teoria de Paulo Freire.

Entre as concepções tradicionais, citam-se as que envolvem desde a pedagogia de Platão e a pedagogia cristã, contemplando as pedagogias dos humanistas e a de Comênio (SUCHODOLSKI, 1978). E tem-se ainda a pedagogia idealista de Kant e Hegel; o humanismo racionalista que se difundiu com a Revolução Francesa; a teoria da evolução; e a sistematização de Herbart-Ziller que desencadeava em uma teoria do ensino (SAVIANI, 2007). Essa concepção pautou-se pela centralidade da instrução, centrada no professor, cuja tarefa era transmitir os conhecimentos acumulados pela humanidade, cabendo aos alunos assimilar os conteúdos recebidos (SAVIANI, 2007).

Além dos aportes de Saviani (2007), as contribuições de Gauthier referendam que "a pedagogia tradicional, portadora de costumes dos séculos passados, define-se como uma prática de saber-fazer conservadora, prescritiva e ritualizada [...]”. (GAUTHIER, 2010, p. 175). Essa concepção centrava-se na instrução, portanto, o professor era o transmissor dos conhecimentos acumulados pela humanidade segundo uma gradação lógica, cabendo aos alunos assimilar os conteúdos que lhes eram transmitidos. Nesse contexto, a prática era determinada pela teoria que a moldava, fornecendo-lhe tanto o conteúdo quanto a técnica de transmissão pelo professor, com a consequente assimilação pelo aluno.

No início do século XIX a pedagogia tradicional foi contestada pela escola nova, que parte para uma visão de ciência, a fim de criar a ciência da educação, contemplando as necessidades da criança, com ênfase na psicologia. Segundo Gauthier, “em suma, a pedagogia nova situa a criança no centro de suas preocupações e se opõe a uma pedagogia tradicional, centrada no mestre e nos conteúdos a transmitir" (2010, p. 175).

Na pedagogia nova, a ênfase estava nas teorias da aprendizagem, no como aprender, generalizado pelo aprender a aprender. As correntes renovadoras, tendo por base seus precursores como Rousseau, Pestalozzi e Froebel (SUCHODOLSKI, 1978).

Centralizando-se no educando, a pedagogia nova contempla a instituição educacional como um espaço aberto à iniciativa dos alunos que constroem sua própria aprendizagem, cabendo ao professor o papel de acompanhá-los, auxiliando-os em seu próprio processo de aprendizagem. Assim, segundo Saviani (2007, p. 104), “o eixo do trabalho pedagógico 
desloca-se da compreensão intelectual para a atividade prática, do aspecto lógico para o psicológico, dos conteúdos cognitivos para os métodos ou processos de aprendizagem”. Essa tendência ganhou força no início do século XX, e tornou-se hegemônica, sob a forma do movimento da Escola Nova até o início da segunda metade desse século.

A pedagogia tecnicista surgiu, no Brasil, especialmente no período de 1960 a 1979, como um contraponto à pedagogia nova, buscando tornar a educação operacional e objetiva. Para compreender essa visão adotam-se os estudos de Kuenzer e Machado (1986) que tecem uma crítica a essa teoria. Segundo esses autores, a pedagogia tecnicista foi implantada no Brasil para atender aos interesses do sistema capitalista, através da necessidade de preparação de mão de obra que pudesse, conforme as demandas das empresas, articular-se diretamente com o sistema produtivo, tendo "[...] a produtividade máxima propiciada pela racionalização do trabalho e do controle sobre ele" (KUENZER; MACHADO, 1986, p. 39). Seu interesse principal era, portanto, produzir indivíduos competentes e treinados para atuar no mercado de trabalho, não se preocupando com as mudanças e contribuições sociais.

Os estudos de Saviani (2007) também corroboram esse olhar crítico à visão da pedagogia tecnicista, pois esta se sustentava na concepção do trabalho fabril, nos pressupostos da objetividade e da racionalidade, buscando minimizar as interferências subjetivas através da mecanização do processo educativo. Nos termos de Saviani (2007, p. 381), a pedagogia tecnicista, ao transpor para a escola "a forma de funcionamento do sistema fabril, perdeu a especificidade da educação, ignorando que a articulação entre escola e o processo produtivo se dá de modo indireto e por meio de complexas mediações”. Desse modo, o reducionismo tecnicista não contempla a complexidade do processo pedagógico, pois restringe as relações das instituições educacionais simplesmente à aplicação de técnicas.

A partir da segunda metade do século XX, surge a teoria de Paulo Freire, que acresce grandes contribuições ao cenário da educação brasileira, destacando-se, principalmente, as contribuições nos processos formativos e nas políticas públicas educacionais de viés dialético, que zelam pelo diálogo, autonomia, emancipação e criticidade. Freire (2000a p. 80) destaca que a "a prática pedagógica requer a compreensão da própria gênese do conhecimento, ou seja, de como se dá o processo de conhecer". Na visão freireana (2009), o diálogo é a categoria principal da construção do conhecimento, que deve perpassar todas as etapas de formação, evitando o risco de que ela se torne um processo de educação bancária, de depósito de conhecimento que reproduz a ideologia dominante e prioriza o diálogo na perspectiva da transformação.

RIAEE - Revista Ibero-Americana de Estudos em Educação, Araraquara, v. 14, n. 1, p. 253-264, jan./mar., 2019. E-ISSN: 1982-5587. 


\section{Percurso investigativo}

A presente investigação contemplou os registros da comemoração do jubileu, 50 Anos do Curso de Pedagogia da UCS, em 2010, que serviram de apoio para historiar as trajetórias dos professores do curso de Pedagogia quanto às suas origens e experiências no processo de constituição de significados, somando-se às do atual corpo docente. Por meio de uma abordagem qualitativa, em desdobramentos da pesquisa documental e autobiográfica, e a respectiva análise discursiva dos dados, foram sistematizados saberes construídos como espaços de memória e de identidade em diferentes contextos de formação.

Fentress e Wickham (1992) destacam as vinculações e relações entre duas dimensões da memória: individual e coletiva, cujos suportes são os indivíduos, pois esses é que se recordam. Dois aspectos são relevantes: a construção de uma versão relembrada_sobre o passado, e sua comunicação e troca, como base do processo. O papel da comunicação na construção da memória social é enfatizado pela "ação de falar ou escrever sobre as recordações, bem como com a reencenação formal do passado" (FENTRESS e WICKHAM, 1992, p.11). Destaca-se a importância da não individualidade do ato de recordar, entendido como um ato social. A memória social está condicionada à existência do significado para o grupo que recorda, e valoriza a subjetividade essencial da memória como questão-chave indicativa por onde começar. Os grupos são analisados internamente, a partir de suas subjetividades, metáforas, sentimentos e valores. Os autores Fentress e Wickham demarcam o lugar da memória como

[...] uma expressão da experiência coletiva; a memória social identifica um grupo, conferindo sentido ao seu passado e definindo suas aspirações para o futuro. $\mathrm{O}$ que é verdade para a memória dos indivíduos também é verdade para a memória social (1992, p. 35).

O exercício de aproximar-se da ponta do fio, que cria a trama de suas vivências, mostra ao professor um cenário de um tempo e de um espaço de formação gerado pelo filtro da memória, pleno de sensações e movimentos. O desafio posto é atribuir significado à construção singular e também múltipla do ser professor.

A possibilidade de levantar as experiências significativas, especificamente no desencadear do percurso profissional, e os respectivos ecos na memória e identidade do corpo docente do Curso de Pedagogia mostraram a relevância do conceito linguagem, a qual compreende as muitas vozes constituidoras da identidade do curso, em um amálgama de inúmeros conhecimentos e múltiplos significados que emergiram na enunciação dos discursos 
produzidos. Conforme Bahktin (1992), o discurso é produto de uma enunciação, realizada por determinado sujeito, em dado tempo e lugar. O texto é a manifestação do discurso. Portanto, analisar o texto é estudar um discurso produzido por uma enunciação radicada em determinada formação social, em determinado momento da história, no caso, da licenciatura em Pedagogia.

Um conceito importante na teoria de Bakhtin (1992) é o dialogismo que se apoia na concepção de linguagem como interação entre quaisquer formas de comunicação verbal. Do ponto de vista discursivo não há enunciado desprovido de dimensão dialógica, porque qualquer enunciado sobre um objeto se relaciona com aqueles anteriores produzidos sobre esse objeto. Portanto todo discurso é fundamentalmente diálogo e os significados são produzidos nas relações dialógicas, na mesma medida que sujeitos e objetos no mundo se constituem sujeitos e objetos do e no mesmo discurso. Nas análises realizadas constatou-se que os depoimentos dialogam entre si.

No entendimento de Tardif (2000), a definição de epistemologia da prática profissional propõe uma volta à realidade, isto é, um processo centrado no estudo dos saberes dos atores em seu contexto real, em situações concretas de ação, nos saberes das suas experiências. Um dos desafios postos à educação e aos educadores, e expresso em princípios legais, é vincular o processo educativo às práticas sociais, ou seja, manter-se em sintonia com o contexto, com as relações e as transformações constantes que ocorrem no mundo. Uma possível resposta a esse desafio implica entender o que se produziu e se produz no meio social e cultural, e, em decorrência, promover maior compreensão das ações realizadas no cotidiano. A trajetória delineada em tempos e espaços pelo grupo de professores depoentes traz consigo a semente da sua identidade, que é única e múltipla, pois reúne processos individuais, coletivos, culturais, sociais e históricos. As diferentes histórias individuais afinam-se no coletivo e tecem sua identidade.

\section{Contextos da Investigação: formação de pedagogos e perspectivas}

A presente investigação contemplou diversos momentos vividos ao longo do período de 50 anos, no cenário de ideias pedagógicas e suas implicações nas cinco décadas de existência do Curso de Pedagogia. Na presente análise utiliza-se um recorte dos relatos de professores que ingressaram no curso nos anos 1960-1970 e de professores em atividade no momento em que o curso completou 50 anos.

RIAEE - Revista Ibero-Americana de Estudos em Educação, Araraquara, v. 14, n. 1, p. 253-264, jan./mar., 2019. E-ISSN: 1982-5587. 
Dentre as categorias discursivas, abordadas nas falas dos sujeitos, identifica-se a ênfase ao contexto histórico, cujos desdobramentos importantes abrangem as reformas de ensino, o modo de acesso aos processos educativos e a formação do corpo docente do curso. Assim, nos registros dos professores aposentados que fazem parte dessa investigação encontra-se presente o movimento das reformas educacionais, especialmente as vividas durante os anos de 1964 e meados de 1970. Nessa época, o ingresso à Faculdade era restrito, havia poucos professores com formação em curso superior para lecionar, em sua maioria egressos do Curso Normal — curso preparatório para o Magistério:

PA 2- O ingresso na Faculdade era muito restrito, a maioria dos professores não tinha curso superior.

PA1 - [...] na Pedagogia é muito difícil, na época o Ensino Superior era muito burocrático. [...] Eu passei por quatro Reformas durante a minha vida. [...] houve todo um movimento de questionamento pedagógico na época que começou no final de 70 . Houve todo aquele movimento de revisão da estrutura de Estado, de política, de estrutura social. [...] a gente trabalhava com alguns teóricos que ficavam questionando a educação e até hoje continuam questionando, só que as soluções não vieram e nós temos o que temos por aí.

A formação de professores, nessa época, foi influenciada pela perspectiva tecnicista de educação. Os cursos de formação de professores centravam-se em um currículo baseado no modelo em que predominava a racionalidade técnica do ensino, permeado pela separação entre a teoria e a prática, pela supervalorização do conhecimento específico. Esse sistema era defensor da classe política que estava no poder, reafirmando a concepção burguesa de educação.

Nesse contexto, duas reformas educacionais — a de 1968 e a de 1971 — propunham, em sua base, o rompimento com a inspiração liberal humanista, presente na LDB de 1961. Ambas carregavam a marca da racionalidade técnica, da fragmentação do ensino e do isolamento do aluno, enfatizando a quantidade, os métodos e técnicas que se conjugavam na formação profissional, acoplada ao processo produtivo e à organização do trabalho.

Essa visão tecnicista não só reduziu a atividade docente e suas competências técnicas como propiciou a visão de substituir os professores por máquinas. Essa visão, segundo Nóvoa (1992), contribuiu para o processo de desprofissionalização, intensificando a crise de identidade profissional, a fragmentação dos processos de ensino e a separação entre o "eu pessoal e o eu profissional". É o que se lê no depoimento de uma professora: 
PA 2 - O fazer da sala de aula era o ponto-chave, mas o ensino e a pesquisa também eram feitos, porque a bibliografia era muito escassa na época. Fazíamos muita pesquisa e muita produção, mas sem a intenção de divulgar.

Nessa fala aparece a preocupação com o ensinar e o saber-fazer; ambos ocupavam o centro do processo pedagógico, tendo a sala de aula como o espaço central para o seu desenvolvimento. Também se observa que havia uma visão de pesquisa mais voltada à busca pelo conhecimento, não estando diretamente vinculada à investigação científica. Essa compreensão do saber-fazer na sala de aula ainda se encontrava presa à concepção moderna de ciência que predominou por longos anos.

Contudo, Santos (1999) aponta que havia a necessidade de ruptura com a visão moderna de ciência, indo ao encontro de uma visão pós-moderna, uma visão que dialogasse com outras formas de conhecimento; valorizasse o conhecimento de senso comum, em que todo o cotidiano orientasse as ações e dessem sentido à vida, tornando o conhecimento emancipatório. Em décadas recentes observa-se o investimento nessa nova visão de ciência e de pesquisa que passou a contribuir para o desenvolvimento de processos de formação e atuação docente.

Os participantes desta pesquisa ${ }_{2}^{3}$ - professores em atividade no curso de Pedagogia, no momento em que o curso completou 50 anos - trouxeram informações relativas à sua carreira docente. O grupo de professores percebia seu papel em três grandes concepções: a) de grande importância e compromisso social; b) uma visão idealista da profissão; e c) a preocupação em promover a aprendizagem dos alunos, exemplificadas nas seguintes falas:

PE2 - A educação é a grande ferramenta da melhoria da sociedade como um todo.

PE3 - Minhas expectativas eram de auxiliar cada aluno(a) a superar suas dificuldades.

PE8 - Acreditava ter as armas de mudar o mundo, que trabalhar com os jovens seria possível fazer a mudança no nosso país, seria possível diminuir as diferenças sociais.

PE9 - [...] de poder fazer a diferença, ouvir os alunos e oportunizar situações de aprendizagem.

Os depoimentos dos docentes sinalizam o compromisso com a aprendizagem dos estudantes e suas relações com a dimensão social. Os estudos de Paulo Freire superam a concepção bancária da educação, pois traz, em seus princípios, as bases para uma educação libertadora, uma educação como prática da liberdade, fundamentada na teoria da ação

${ }^{3}$ Docentes lotados e atuando no curso são identificados pela sigla PE - professores efetivos, seguida de dígito numérico. 
dialógica. Defendem, ainda, que essa educação contribua para que homes e mulheres atuem juntos na luta para alcançar a libertação. Seguindo essa visão inserem-se as seguintes contribuições dos docentes ao dialogarem sobre o exercício da docência:

PE4 - Promover a autonomia, a amorosidade, a militância política e a pesquisa em sala de aula.

PE10 - Acreditava na educação popular e na educação política das classes menos favorecidas.

PE11 - A grande responsabilidade com os alunos e a transformação de suas condições de vida. O professor é mediador do conhecimento e da militância na transformação das desigualdades sociais.

Desse modo, constata-se, nas afirmações destacadas pelos professores, que a docência deva contribuir para promover a autonomia, a dimensão social e política, colaborando para a superação das desigualdades sociais. Também destacaram a importância de promover a pesquisa em sala de aula, confirmando o legado de Freire: "Ensinar exige pesquisa" (2009, p. 29).

Os depoimentos dos docentes do curso de Pedagogia também foram analisados à luz das atuais Diretrizes Nacionais para o Curso de Graduação em Pedagogia, a fim de compreender as visões prospectadas pelos professores formadores. Nos relatos dos docentes está explícito o encontro das concepções e práticas exercidas com as novas Diretrizes Curriculares do Curso de Pedagogia, aprovadas em 2006.

Ao se questionar o docente em relação à identidade profissional atual, em relação as suas expectativas/ crenças, ideais e valores pedagógicos, tem-se: "continuo crendo na mudança, mas agora em âmbito maior, de políticas públicas, de articulações, pois a estrutura política e econômica já desenvolveram dispositivos que podem capturar as iniciativas de grupos pequenos."(PE8)

O depoimento acima expressa a postura do profissional perante a forma de ensinar e estar sempre atento às demandas que venham a surgir. Também Freire (2009) diz que a pesquisa é fundamental para se ensinar: "não há ensino sem pesquisa e pesquisa sem ensino. Esses fazeres se encontram um no corpo do outro. Enquanto ensino, continuo buscando, reprocurando" (2009, p. 20).

Nóvoa (1995) cita, como caráter correlacional, o comportamento dos professores em relação à repercussão dos alunos em sala de aula. Portanto é necessária uma estratégia pedagógica para se investir no sujeito docente, para que ele possa desenvolver suas competências e fomentar expectativas positivas no contexto educacional. 
Os docentes aqui citados também fazem uma interlocução com as Diretrizes Curriculares (2006, p. 01), em cujo recorte se lê: "Para a formação do licenciado em Pedagogia é central: I - o conhecimento da escola como organização complexa que tem a função de promover a educação para e na cidadania; II - a pesquisa, a análise e a aplicação dos resultados de investigações de interesse da área educacional".

É fundamental, portanto, que o profissional de pedagogia priorize o conhecimento contextualizado, a pesquisa e o planejamento dentro do ambiente educacional, visando compreender as problemáticas existentes no meio em que está inserido e desencadear alternativas em prol de melhorias no modo de ensinar, consideradas as condições que o contexto oferece.

Em relação à identidade profissional atual e seus respectivos desafios, em seu depoimento PE10 afirma: "a continuidade dos estudos com grupo de professores [...]. Manter diálogo entre colegas do ensino superior para motivar momentos de pesquisa e produção acadêmica em nível de graduação". Isso demonstra preocupação com a formação continuada e a necessidade de interação entre os profissionais.

Segundo Freire (2009), para ensinar é preciso respeitar os saberes dos educandos, aproveitar suas experiências em relação ao contexto em que a escola se encontra. Nesse sentido, no decorrer das análises dos depoimentos constatou-se que a pesquisa é considerada um princípio pedagógico, a qual exerce importante papel para auxiliar a prática do docente em sala de aula. Portanto, evidencia-se a importância de trabalhar com a pluralidade de conhecimentos teóricos e práticos, fundamentados em princípios da interdisciplinaridade, da ética e da cidadania, que colaboram para os diversos aspectos sociais e educacionais imbricados nos processos de ensino e aprendizagem.

\section{Considerações finais}

Nos últimos 50 anos a formação de professores ocorria em ambiente movido por ideais de concepção tecnicista. Os cursos de formação de professores centravam-se em um currículo baseado no modelo em que predominava a racionalidade técnica do ensino, em que havia a separação entre a teoria e a prática; a supervalorização do conhecimento específico e o isolamento do aluno, enfatizando a quantidade, os métodos e técnicas que se conjugavam na formação profissional acoplada ao processo produtivo e à organização do trabalho. 
Observou-se que houve uma evolução nas últimas duas décadas, que contou com o apoio de novas tendências pedagógicas e das políticas educacionais. No decorrer do exercício profissional, os professores foram se especializando, em busca de uma formação continuada, nem sempre acessível ou facilitada, e o ingresso no mundo acadêmico ainda não dependia exclusivamente da qualificação em nível de mestrado ou doutorado. A aprendizagem dos conteúdos, que centralizava as preocupações e os saberes da experiência, estava bem presente, oferecendo garantias à profissão.

Em contrapartida, as vozes do corpo docente em atividade no curso de Pedagogia, no momento em que o curso completou 50 anos, e que participaram desta investigação, manifestaram suas dificuldades em tratar desses desafios impostos à profissão, e expressaram a responsabilidade em formar os futuros pedagogos, estimulando habilidades e competências inerentes ao exercício profissional. Na condição de corpo coletivo, esses docentes pretendem ser referência no esforço do comprometimento profissional com a educação. Neles permanece a esperança de contribuir, e o esforço para dar conta das novas demandas e expectativas dos estudantes e da própria sociedade, e sinalizam marcas de transição de paradigmas.

Ao se projetar a formação docente para o futuro, os resultados deste estudo indicam a necessidade de investimento no ensino com pesquisa, de promoção do conhecimento, de atualização constante, com ênfase nos processos de humanização. A atuação do pedagogo e a função docente se revestem de forte compromisso com a dimensão social, além do aspecto didático e pedagógico, diante das transformações provocadas pelas forças externas ao meio acadêmico, de natureza complexa diante das relações possíveis, sejam elas de ordem política, econômica, cultural ou histórica, entre tantas outras possíveis.

\section{REFERÊNCIAS}

BRASIL. Decreto $\mathbf{n}^{\mathbf{0}}$. 47668, de 19 de janeiro de 1960, publicado no DOU de 25 de janeiro de 1960.

BRASIL. Decreto n ${ }^{\circ}$ 55665, de 01/02/65, publicado no DOU de 16/02/65.

BRASIL. Ministério da Educação e da Cultura. Diretrizes Curriculares Nacionais para o Curso de Graduação em Pedagogia, licenciatura. Resolução. CNE/CP nº 1, de 15 de maio de 2006.

BAKHTIN, M. Marxismo e filosofia da linguagem. 6. ed. São Paulo: Hucitec, 1992.

FENTRESS, J.; WICKHAM, C. Memória social. Lisboa: Teorema, 1992. 
FONTANA, R. A. C. Como nos tornamos professoras? Belo Horizonte: Autêntica, 2000.

FREIRE, P. A educação na cidade. 4. ed. São Paulo: Cortez, 2000a.

FREIRE, P. Educação e Mudança. Rio de Janeiro: Paz e Terra, 2006a.

FREIRE, P. Pedagogia da Autonomia: saberes necessários à prática educativa. São Paulo: Paz e Terra, 2009.

SAVIANI, D. Pedagogia: o espaço da educação na universidade. Cad. Pesqui. [online]. 2007, vol.37, n.130, p.99-134. ISSN 0100-1574. Disponível em: http://dx.doi.org/10.1590/S010015742007000100006. Acesso em: 25 fev. 2018.

SAVIANI, D. A pedagogia no Brasil: história e teoria. Campinas, SP: Autores Associados, 2008.

KUENZER, A.Z.; MACHADO, L.R. de S. A pedagogia tecnicista In: MELO, G. (org.). Escola Nova; tecnicismo na educação compensatória. São Paulo: Loyola, 1986.

NÓVOA, A. Formação de professores e profissão docente. In: NÓVOA, A. (org.). Os professores e sua formação. Lisboa: Nova Enciclopédia, 1992.

SANTOS, B.de S. Um discurso sobre as ciências. Porto: Edições Afrontamento, 1999.

SNYDERS, G. Para onde vão as pedagogias não diretivas? 2. ed. Lisboa: Moraes, 1978.

SUCHODOLSKI, B. A pedagogia e as grandes correntes filosóficas. 2. ed. Lisboa: Livros Horizonte, 1978.

TARDIF, M. Saberes docentes e formação profissional. Petrópolis, RJ: Vozes, 2000.

\section{Como referenciar este artigo}

MORÉS, A.; PANOZZO, N. S. P. Formação de pedagogos: trajetórias e perspectivas docentes. Revista Ibero-Americana de Estudos em Educação, Araraquara, v. 14, n. 1, p. 253-264, jan./mar., 2019. E-ISSN: 1982-5587. DOI: 10.21723/riaee.v14i1.11247

Submissão: $27 / 03 / 2018$

Revisões requeridas: $30 / 05 / 2018$

Aprovação final: 15/08/2018 